\title{
Characterization of cassava biopolymers and the determination of their optimum processing temperatures
}

\begin{abstract}
This work reports the characterisation of cassava biopolymers. Moreover, the effects of processing temperature on the tensile properties and phase morphology of cassava biopolymers were investigated. Eight different temperatures were selected as processing temperatures in sample preparation of the cassava biopolymers. Variance analysis justifies that 165 and $170^{\circ} \mathrm{C}$ are the optimum processing temperatures in producing maximum tensile properties. The present study reveals that the range of processing temperatures for cassava biopolymer was relatively lower as compared to the majority of the petroleum-based polymer. However, its low processing temperature makes this biopolymer has enormous potential in the development of fully biodegradable composites.
\end{abstract}

Keyword: Word; Cassava biopolymer; Starch-based polymer; Optimum processing temperature; Material processing 